\title{
Quality of Life Assessment After HSCT for Pediatric and Adults
}

\author{
Anna Barata and Heather Jim
}

\subsection{Introduction}

Methodological advances in the HCT field have increased the population of survivors worldwide. However, HCT is associated with significant morbidity that impairs survivors' recovery and adversely affects their QoL. A significant body of literature has addressed QoL after HCT and highlights significant deficiencies in physical, psychological, social, and role functioning both in adult and pediatric survivors (Pidala et al. 2010). These data are clinically relevant as they help to understand the impact of HCT on patient's lives. Clinically, assessment of QoL can inform patient education and be used to evaluate the benefit of supportive care interventions.

\subsection{QoL Assessment}

QoL can be considered a patient-reported outcome (PRO). PROs are defined by the US Food

\author{
A. Barata $(\square)$ \\ Department of Hematology, Hospital de la Santa \\ Creu i Sant Pau, Universitat Autònoma de Barcelona, \\ Barcelona, Spain \\ José Carreras Leukemia Research Institute, \\ Barcelona, Spain \\ e-mail: ABarata@santpau.cat \\ H. Jim \\ Department of Health Outcomes and Behavior, \\ Moffitt Cancer Center, Tampa, FL, USA
}

and Drug Administration (FDA) as the "measurement of any aspect of a patient's health status that comes directly from the patient, without the interpretation of the patient's response by a clinician or anyone else" (US Food and Drug Administration 2009). Thus, PROs specifically describe the impact that HCT has on patients' lives and provide information unavailable from other sources (Kurosawa et al. 2017; Russell et al. 2006). PROs are also used in pediatric populations, although parents or other proxies might be used as source of information when children are unable to report their own QoL. However, the use of patients' own reports is clearly recommended because significant discrepancies are found when comparing patients' self-reported QoL to reports of physicians, parents, or other proxies (Kurosawa et al. 2017; Russell et al. 2006). In general, measures to assess patient- and proxy-reported QoL are questionnaires.

These instruments can be broadly categorized as general or disease- or procedure-specific. General measures assess QoL of the general population and can also be administered to specific populations, such as HCT recipients. These questionnaires allow comparisons of QoL across populations, such as between HCT survivors and individuals without cancer. In contrast, diseaseand procedure-specific instruments examine specific aspects of the health conditions assessed. These measures capture specific PROs that are likely to be important to patients. 


\subsection{Measures to Assess QoL in Adults and Pediatric Patients Undergoing HCT}

There are numerous measures assessing QoL on adults and pediatric HCT recipients. Measures used have been both general and disease-specific. The following sections list some of the most common used questionnaires in the field of HCT.

\subsubsection{Adults}

Interest in assessing QoL in adult $\mathrm{HCT}$ recipients is reflected in the variety of measures used to assess this outcome. However, there is a need for the scientific community to reach consensus about which questionnaires to use in order to facilitate comparison across studies (Shaw et al. 2016). Table 34.1 summarizes alphabetically some of the most common questionnaires to assess $\mathrm{QoL}$ in adults.

Table 34.1 QoL questionnaires assessing QoL in adult HCT survivors

\begin{tabular}{|c|c|}
\hline \multicolumn{2}{|l|}{ (a) General } \\
\hline \multicolumn{2}{|c|}{ European Quality of Life- 5 Dimensions (EQ-5D-5L) (van Reenen and Jansen 2015) } \\
\hline Aim & Health status \\
\hline Items & 6 \\
\hline Domains/subscales & Mobility, self-care, usual activities, pain, anxiety, depression \\
\hline Results & $\begin{array}{l}\text { Profile of each of the domains assessed, and an index of the health status. } \\
\text { Higher scores indicate better health status }\end{array}$ \\
\hline Translations & Available in more than 130 languages \\
\hline \multicolumn{2}{|c|}{ Medical Outcomes Study-Short Form (MOS SF-36) (Ware et al. 1994) } \\
\hline Aim & QoL \\
\hline Items & 36; shorter versions feature 12 items (SF-12) or 8 items (SF-8) \\
\hline Domains/subscales & $\begin{array}{l}\text { General health, physical, role, emotional and social functioning, mental } \\
\text { health, pain, vitality }\end{array}$ \\
\hline Results & $\begin{array}{l}\text { Physical Component Score; Mental Component Score and Global Score. } \\
\text { Higher scores indicate better QoL }\end{array}$ \\
\hline Translations & Available in more than 170 languages \\
\hline \multicolumn{2}{|c|}{ Patient-Reported Outcomes Measurement Information System (PROMIS) (Cella et al. 2010) } \\
\hline Aim & $\begin{array}{l}\text { Mental, physical, and social health and QoL in healthy populations as well } \\
\text { as those with chronic conditions }\end{array}$ \\
\hline Items & $\begin{array}{l}\text { Multi-item measures varying } \\
\text { in length and complexity; } \\
\text { for example, PROMIS- } 29 \\
\text { has } 29 \text { items, PROMIS- } 43 \\
\text { has } 43 \text { items, PROMIS-57 } \\
\text { has } 57 \text { items }\end{array}$ \\
\hline Domains/subscales & $\begin{array}{l}\text { Each subscale measures a single domain; PROMIS Profile measures } \\
\text { assess multiple domain }\end{array}$ \\
\hline Results & $\begin{array}{l}\text { Higher scores indicate more of the concept being measured. Measures use } \\
\text { standardized T-score metric against normative data for the US population }\end{array}$ \\
\hline Translations & Available in Spanish and several other languages \\
\hline \multicolumn{2}{|c|}{ (b) Cancer and HCT specific } \\
\hline \multicolumn{2}{|c|}{$\begin{array}{l}\text { European Organization for Research and Treatment of Cancer QoL Questionnaire Core } 30 \text { (EORTC QLQ-C30) } \\
\text { version 3.0 (Aaronson et al. 1993) }\end{array}$} \\
\hline Aim & QoL in cancer \\
\hline Items & 30 items \\
\hline Domains/subscales & Functional scales, symptom scale and a QoL scale \\
\hline Results & $\begin{array}{l}\text { Higher scores in functional and QoL scales indicate better wellbeing. } \\
\text { Higher scores in the symptom scale indicate worse symptomatology }\end{array}$ \\
\hline Translations & Available in more than 100 languages \\
\hline
\end{tabular}


Table 34.1 (continued)

\begin{tabular}{l|l|}
\begin{tabular}{l} 
Functional Assessment of Cancer Therapy-Bone Marrow Transplant (FACT-BMT) (McQuellon et al. 1997) \\
\hline $\begin{array}{l}\text { Aim } \\
\text { Items }\end{array}$
\end{tabular} & QoL in HCT \\
\hline $\begin{array}{l}\text { Domains/subscales } \\
\text { Consists of the FACT-G (Cella et al. 1993) and the BMT concerns } \\
\text { subscale }\end{array}$ \\
\hline $\begin{array}{l}\text { Results } \\
\text { Translations }\end{array}$ & Available in more than 38 languages \\
\hline Functional Assessment of Cancer Therapy-General Scale (FACT-G) (Cella et al. 1993) \\
\hline Aim & QoL in cancer \\
\hline Items & 33 \\
\hline Domains/subscales & Physical, functional, social and emotional well-being \\
\hline Results & Higher scores indicate better wellbeing and global QoL \\
\hline Translations & Available in more than 60 languages \\
\hline
\end{tabular}

\subsubsection{Pediatrics}

There is less research on QoL on pediatric patients than adult patients. Initial pediatric studies focused on a single aspect of functioning, such as psychosocial and physical limitations. It was not until the early 1990s that pediatric QoL began to be addressed as a multidimensional construct. Most of the measures used in pediatric studies were originally developed to be used in the general population or in children with specific illnesses. Table 34.2 lists alphabetically the most common measures used to assess QoL in pediatric population.

\subsection{Challenges when implementing QoL assessment}

Improvement in patients' QoL is included among the strategic goals of major cancer organizations such as the American Society of Clinical Oncology and regulatory agencies such as the FDA and the European Medicines Agency. Recognition of the importance of the patient experience is reflected in the increasing incorporation of patient-reported QoL measures in observational research and clinical trials. However, some aspects should be considered when implementing patient-reported QoL measures.

Historically, studies and clinical trials performed in the USA have often used the FACT instruments, whereas studies performed in Europe have chosen the EORTC. This divergence makes results difficult to compare (Shaw et al. 2016), although efforts are underway to map common QoL measures such as the EORTC QLQ-C30 and FACT-G to one another (Young et al. 2015). Second, the mode of administration should also be considered. PRO measures have traditionally been administered by paper and pencil, but new technologies offer the potential to use electronic measures. Electronic measures administered before or during a clinic visit allow results to be available at the time of consultation and may facilitate symptom monitoring to guide supportive treatment. One example is the PROMIS instrument, which is available using computer adaptive testing or through REDCap software. Computer adaptive testing selects questions based on the previous responses that patients have provided to approximate the construct being measured in the fewest number of questions. The implementation of routine assessment of patients' QoL on clinical care and clinical trials has the potential to improve patients' well-being. 
Table 34.2 QoL questionnaires assessing QoL in pediatric HCT survivors

(a) General

Child Health Questionnaire (CHQ) (Landgraf et al. 1996)

Aim

\begin{tabular}{l|l} 
Versions & $\begin{array}{l}\text { Parent-reported versions feature 50 items (CHQ-PF50) or 28 items (CHQ-PF28) and are } \\
\text { intended for parents of children aged 5-18 years. The child-report version (CHQ-87) has 87 } \\
\text { items and is appropriate for children aged 10-18 }\end{array}$ \\
\hline Domains/subscales & $\begin{array}{l}\text { Global health, physical functioning, role/social-physical functioning, bodily pain/ } \\
\text { discomfort, role/social-emotional functioning, role/social -behavior, parental impact } \\
\text {-time, parental impact -emotional, self-esteem, mental health, global behavior, family } \\
\text { activities, family cohesion, and changes in health }\end{array}$ \\
\hline Results & $\begin{array}{l}\text { Higher scores indicate higher physical and psychosocial wellbeing } \\
\text { Translations }\end{array}$ \\
\hline
\end{tabular}

QoL

Patient-Reported Outcomes Measurement Information System (PROMIS) (Hinds et al. 2013)

Aim

Health and QoL in healthy populations as well as those with chronic conditions
Versions
Multi-item measures varying in length and complexity: PROMIS-25 has 25 items, PROMIS-37 37 items, and PROMIS-49 49 items. PROMIS measures are child- and parent-reported.
Child-report measures are intended for children aged 8-17, and parent-report for children 5-17
Domains/subscales Physical, mental and social health, and a global QoL score
Results
Higher scores indicate more of the concept being measured. PROMIS use standardized
T-score metric against normative data for the US population
Translations $\quad$ Children and proxy measures are available in Spanish and in several other languages
Pediatric Quality of Life Inventory (PedsQL ${ }^{\mathrm{TM}}$ ) 4.0 Generic Score Scales (Varni et al. 2001)
Aim
QoL in healthy children or those diagnosed with an acute or chronic disease
Versions
Parent-report form for children aged 2-4 has 21 items, and child and parent reports for children aged 5-18 have 23 items
Domains/subscales
Results
Physical, emotional, social, and school functioning
Translations
Physical health summary score; Psychosocial health summary score; Total score. Higher scores indicate better QoL

(b) Cancer and HCT specific

Child Health Rating Inventories (CHRIs)-and Disease-Specific Impairment Inventory-Hematopoietic Stem Cell Transplantation (DSII-HCT) (Parsons 2005)

Aim

The disease specific (DSII-HCT) module assesses QoL of childhood HCT survivors

Versions

10-item module intended to child-report (aged 5-12), adolescent-report (13-18) and parents-report (5-18)

Domains/subscales Items are grouped in three domains reported by parents and patients to be most salient to the HCT experience: worry, hassless, and body image

Results Higher scores indicate better QoL

Translations $\quad$ The questionnaire is available in English

Peds Quality of Life Cancer Module 3.0 (PedsQL CMTM) (Varni et al. 2002)

Aim

Versions

QoL in children with cancer

Versions

Parent-report form for children aged 2-4 has 25 items, child and parent reports for children aged 5-7 has 26 items, and child and parents reports for children more than 8 years has 27 items

Domains/subscales Pain and hurt, nausea, procedural anxiety, treatment anxiety, worry, cognitive problems, perceived physical appearance and communication

Results Higher scores indicate better QoL

Translations Available in more than 100 languages

The Behavioral, Affective and Somatic Experiences Scales (BASES) (Phipps et al. 1994)

Aim

Versions

QoL during the acute phase of HCT

Versions

There are separate versions to be completed by nurses (BASES-N), parents (BASES-P) and children (BASES-C). The BASES-N and BASES-P have 38 items and the BASES-C has 14 items. The questionnaire is intended to be used in child aged 5-17

Domains/subscales Somatic distress, mood disturbance, compliance, quality of interactions and activities

Results

Translations Higher scores indicate more distress/impairment Available in English 


\section{Key Points}

- Assessing HCT survivors' QoL is essential in order to know the impact that the HCT, its morbidity, its treatments, and related interventions have on survivors' well-being.

- Enhanced efforts should be made to in order to include QoL assessment in routine clinical practice. Engaging clinicians in using QoL assessments, potentially by means of electronic administration, as well as broadening the interpretation of their scores into the clinical field, might facilitate incorporation.

- Further efforts should elucidate to what extent QoL results are incorporated into management decisions, treatment recommendations, and patients' education.

- Additional efforts should also be made to include QoL outcomes in clinical trials.

- The incorporation of QoL assessment into clinical and research practice has the potential to improve HCT outcomes.

\section{References}

Aaronson NK, Ahmedzai S, Bergman B, et al. The European Organization for Research and Treatment of Cancer QLQ-C30: a quality-of-life instrument for use in international clinical trials in oncology. J Natl Cancer Inst. 1993;85:365-76.

Cella D, Riley W, Stone A, et al. The Patient-Reported Outcomes Measurement Information System (PROMIS) developed and tested its first wave of adult self-reported health outcome item banks: 2005-2006. J Clin Epidemiol. 2010;63:1179-94.

Cella DF, Tulsky DS, Gray G, et al. The Functional Assessment of Cancer Therapy scale: development and validation of the general measure. J Clin Oncol. 1993;11:570-9.

Hinds PS, Nuss SL, Ruccione KS, et al. PROMIS pediatric measures in pediatric oncology: valid and clinically feasible indicators of patientreported outcomes. Pediatr Blood Cancer. 2013;60: 402-8.

Kurosawa S, Oshima K, Yamaguchi T, et al. Quality of life after allogeneic hematopoietic cell transplantation according to affected organ and severity of chronic graft-versus-host disease. Biol Blood Marrow Transplant. 2017;23:1749-58.
Landgraf JM, Abetz L, Ware JE. Child health questionnaire (CHQ): a user's manual. Boston: Health Institute, New England Medical Center; 1996.

McQuellon RP, Russell GB, Cella DF, et al. Quality of life measurement in bone marrow transplantation: development of the Functional Assessment of Cancer Therapy-Bone Marrow Transplant (FACT-BMT) scale. Bone Marrow Transplant. 1997;19:357-68.

Parsons SK, Shih MC, Mayer DK, Barlow SE, Supran SE, Levy SL, Greenield S, Kaplan SH. Preliminary psychometric evaluation of the Child Health Ratings Inventory (CHRIs) and Disease-Specific Impairment Inventory-Hematopoietic Stem Cell Transplantation (DSII-HSCT) in parents and children. Qual Life Res. 2005;14(86):1613-25.

Phipps S, Hinds PS, Channell S, et al. Measurement of behavioral, affective, and somatic responses to pediatric bone marrow transplantation: development of the BASES scale. J Pediat Oncol Nurs. 1994;11:109-17; discussion 118-119.

Pidala J, Anasetti C, Jim H. Health-related quality of life following haematopoietic cell transplantation: patient education, evaluation and intervention. Br J Haematol. 2010;148:373-85.

van Reenen M, Jansen B. EQ-5D-5L user guide. Basic information on how to use the EQ-5D-5L instrument [Internet]. 2015 [cited 2018 Jan 24]. https:// euroqol.org/wp-content/uploads/2016/09/EQ-5D-5L_ UserGuide_2015.pdf. Accessed 12 Feb 2018.

Russell KMW, Hudson M, Long A, et al. Assessment of health-related quality of life in children with cancer: consistency and agreement between parent and child reports. Cancer. 2006;106:2267-74.

Shaw BE, Lee SJ, Horowitz MM, et al. Can we agree on patient-reported outcome measures for assessing hematopoietic cell transplantation patients? A study from the CIBMTR and BMT CTN. Bone Marrow Transplant. 2016;51:1173-9.

US Food and Drug Administration. Guidance for industry: patient-reported outcome measures: use in medical product development to support labeling claims. US Department of Health and Human Services. Food and Drug Administration. 2009. https://www.fda. gov/downloads/drugs/guidances/ucm 193282.pdf. Accessed 12 Feb 2018.

Varni JW, Burwinkle TM, Katz ER, et al. The PedsQL in pediatric cancer: reliability and validity of the Pediatric Quality of Life Inventory generic core scales, multidimensional fatigue scale, and cancer module. Cancer. 2002;94:2090-106.

Varni JW, Seid M, Kurtin PS. PedsQL 4.0: reliability and validity of the Pediatric Quality of Life Inventory version 4.0 generic core scales in healthy and patient populations. Med Care. 2001;39:800-12.

Ware JE, Kosinski M, Keller S. SF-36 physical and mental health summary scales: a user's manual. Boston: Health Institute; 1994.

Young TA, Mukuria C, Rowen D, et al. Mapping functions in health-related quality of life: mapping from two cancer-specific health-related quality-oflife instruments to EQ-5D-3L. Med Decis Mak. 2015;35:912-26. 
Open Access This chapter is licensed under the terms of the Creative Commons Attribution 4.0 International License (http://creativecommons.org/licenses/by/4.0/), which permits use, sharing, adaptation, distribution and reproduction in any medium or format, as long as you give appropriate credit to the original author(s) and the source, provide a link to the Creative Commons license and indicate if changes were made.

The images or other third party material in this chapter are included in the chapter's Creative Commons license, unless indicated otherwise in a credit line to the material. If material is not included in the chapter's Creative Commons license and your intended use is not permitted by statutory regulation or exceeds the permitted use, you will need to obtain permission directly from the copyright holder.

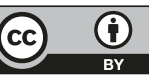

